\title{
Formulation and Evaluation of Anticancer Drug (Tamoxifen) Loaded Nanosponges
}

\author{
B. Raja Narender", P. Raja Sridhar ${ }^{1}$ \\ 1.Shri Jagdish Prasad Jhabarmal Tibrewala University, Vidyanagari, Jhunjhunu, Rajasthan- \\ 333001 .
}

\begin{abstract}
The purpose of this research was to prepare Tamoxifen loaded Nanosponge gel for Sustained release of drug, increase the drug solubility, and increase the drug permeability, to reduce the dosing frequency and side effects. The FTIR studies proved that there were no interactions between the drug and Polymers. Homogenization technique followed by centrifugation was employed to prepare Nanosponge using various polymers. The formulation were prepared using different Polymers (hydroxy Ethyl cellulose and PVA) in different ratios (Drug: Polymer-1:1, 1:1.5, 1:2, 1:2.5, 1:3, 1:3.5, 1:4 and 1:4.5) Using dichloromethane as cross linker as well as solvent. The formulations were characterized for drug entrapment efficiency. The Drug content of the formulations was observed to be from 62.90 to 95.94 . The entrapment efficiency was found to be 68.97 to 99.44 . The highest entrapment efficiency was observed with 98.68 and 99.44 for the formulations F4 and F8. The particle size analysis done by Malvern Zeta sizer showed that the average particle size of Tamoxifen loaded Nanosponge F3 average particle size of Tamoxifen loaded Nanosponge is $91.34 \mathrm{~nm}$ and the poly dispersity index was found to be 0.196 and F8 average particle size of Tamoxifen Nanosponge F7 was 201.34nm and the poly dispersity index was found to be0.178. The in-vitro release of Tamoxifen Nanosponge optimized formulation F4 was found to be $46.39 \%$ and F8was $45.56 \%$ at the end of 24 hours. The drug content of the Gel G1and G2 was found to be $84 \%$ and $81 \%$ respectively. The in-vitro release of Doxorubicin Nanosponge Gel formulation G1 was found to be $28.77 \%$ and G2 was $22.12 \%$ at the end of 24hours. The pH of the gels G1 and G2 was found to be 4.98 and 4.82 respectively. The Viscosity of the gels G1 and G2 was found to be $2.839 \times 10^{6} \mathrm{cps}$ and $2.823 \times 10^{6}$ cps respectively. Both of the optimized formulations of the respected drugs followed first order release kinetics with hi-guchi mechanism. In-vivo test performed showed that the both the formulations of respected drugs able to retain the drug for prolonged periods of time to provide stable drug release and bioavailability
\end{abstract}

Keywords: Tamoxifen, Nanosponge, Gel etc.

*Corresponding Author Email: rajanarenderbongoni@gmail.com

Received 1 November 2019, Accepted 10 November 2019

Please cite this article as: Narender BR et al., Formulation and Evaluation of Anticancer Drug (Tamoxifen) Loaded Nanosponges. American Journal of Pharmacy \& Health Research 2019. 


\section{INTRODUCTION}

The Drug delivery system refers to a system for transporting pharmaceutical compound in the body to provide a desired and required therapeutic effect. Drug delivery is a concept integrated with dosage form and route of administration of pharmaceutical products. The technologies involved in the formulation of pharmaceutical products modify drug release profile, absorption, distribution and elimination for the benefit of improving product efficacy and safety, as well as patient convenience and compliance. Drug release is from: diffusion, degradation, swelling, and affinity-based mechanisms. Most common routes of administration are non- invasive peroral (through the mouth), topical (skin), trans mucosal (nasal, buccal/sublingual, vaginal, ocular and rectal) and inhalation routes. ${ }^{1}$ The aim of Novel Drug Delivery System is to provide a therapeutic amount of drug to the appropriate site in the body to accomplish promptly and then maintain the desired drug concentration. The drug-delivery system should deliver drug at a rate control by the necessarily of the body over a specified term of treatment. ${ }^{2}$ This idealized objectives witch to the two aspects most important to drug delivery are as follows, ${ }^{2}$

Because of their nonporous structure, nanosponges can advantageously carry water insoluble drugs (Biopharmaceutical Classification System class-II drugs). These complexes can be used to increase the dissolution rate, solubility and stability of drugs, to mask unpleasant flavors and to convert liquid substances to solids. $\beta$-Cyclodextrin based nanosponges are reported to deliver the drug to the target site three to five times more effectively than direct injection ${ }^{2}$. Drugs which are

particularly critical for formulation in terms of their solubility can be successfully delivered by loading into the Nanosponges.

The nanosponges are solid in nature and can be formulated as Oral, Parenteral, Topical or Inhalation dosage forms. For the oral administration, the complexes may be dispersed in a matrix of excipients, diluents, lubricants and anticaking agents suitable for the preparation of capsules or tablets ${ }^{9}$. For the parenteral administration the complex may be simply carried in sterile water, saline or other aqueous solutions ${ }^{9}$. For topical administration they can be effectively incorporated into topical hydrogel.

\section{Advantages of Nanosponges ${ }^{11-12}$}

- Targeted site specific drug delivery.

- This Technology offers entrapment of wide variety of ingredients and reduced side effects.

- Improved Stability, increased elegance and enhanced formulation flexibility. 
- Nanosponge systems are non-irritating, non-mutagenic, non-allergenic and non-toxic.

- A Nanosponge provides continuous action up to 12 hours i.e. extended release.

- It minimizes the irritation and it gives better tolerance which leads to improved patient compliance.

- Allows incorporation of immiscible liquids which improves material processing. Liquid can be converted to powders.

- These formulations are stable over wide range of PH (1-11) and temperature (up to $\left.130^{\circ} \mathrm{c}\right)$.

- These are self-sterilizing as their average pore size is $0.25 \mu \mathrm{m}$ where bacteria cannot penetrate.

- These are free flowing, highly compatible with wide variety of ingredients and cost effective.

- They have better thermal, physical and chemical stability.

- Nanosponge particles are soluble in water, so encapsulation can be done within the nanosponge, by the Addition of chemical called an adjuvant reagent.

The aim of the present work is to prepare Nanosponges loaded with anti cancer drugs (Tamoxifen) for topical delivery

Tamoxifen is one of the selective estrogen receptor modulators (SERM) with tissue-specific activities for the treatment and prevention of estrogen receptor positive breast cancer. Tamoxifen acts as an anti-estrogen (inhibiting agent) in the mammary tissue, but as an estrogen (stimulating agent) in cholesterol metabolism, bone density, and cell proliferation in the endometrium. Tamoxifen belongs to a class of drugs called selective estrogen receptor modulators (SERMs), which have both estrogenic and anti estrogenic effects. Tamoxifen has the same nucleus as diethylstilbestrol but possesses an additional side chain (Trans isomer) which accounts for its anti estrogenic activity.

\section{List of Materials Used}

Tamoxifen, Ethyl cellulose, Polymethyl methacrylate, Polyvinyl alcohol, Dichloromethane, Dimethyl sulfoxide, Potassium dihydrogen ortho phosphate, Disodium hydrogen ortho phosphate, Methanol, Dialysis Bag (LA653), Carbopol 934, Glycerin, Triethanolamine. All the ingredients are the gift samples received from Karthikeya drugs and pharmaceuticals pvt. Ltd. Hyderabad. 


\section{METHOD}

\section{Solubility analysis}

Preformulation solubility analysis is to be done, which include the selection of a suitable solvent, to dissolve the respective drug as well as various excipients used since the invention of Nanoparticles.

\section{COMPATIBILITY STUDIESFOR DRUG ANDEXCIPIENTS}

For the development of formulation dosage form, preformulation studies were carried out to confirm no interaction between the drug and excipients. It gives information needed for selection of excipients with the drug for the formulation of Nanosponge. Physical compatibility of the drug with excipients was done. The possibility of drug excipients (Ethyl cellulose and Polymethyl methacrylate) interaction was investigated by FT-IR Spectrum study.

\section{Physical Compatibility}

Physical compatibility of the drug and excipients were carried at Room temperature and at $40^{\circ} \mathrm{C} \pm 2^{\circ} \mathrm{C} / 75 \pm 5 \% \mathrm{RH}$ (in days) with the physical admixture of drug and excipients.

\section{Fourier Transforms Infrared (FT-IR) Spectroscopic studies}

The spectroscopic studies were carried out to find out the interaction between pure drug, excipients and its physical mixture by KBr pellet technique using FT-IR spectrophotometer. The IR spectrum of the physical mixture is then compared with the spectrum of pure drug (Tamoxifen) to assess the compatibility of the excipients and drug. The scanning range is 450$4000 \mathrm{~cm}^{-1}$ and the resolution is $4 \mathrm{~cm}^{-1}$.

\section{Differential Scanning Calorimetry (DSC) studies}

Thermograms were obtained by using a scanning calorimeter (New Castle, United States TA 60) at a heating rate $10^{\circ} \mathrm{c} / \mathrm{min}$. Over a temperature range of $35-400^{\circ} \mathrm{c}$. The sample should be hermetically sealed in an aluminum crucible. Nitrogen gas will be used to purge at a rate of 10 $\mathrm{ml} / \mathrm{min}$ for maintaining inert atmosphere.

\section{PREPARATION OF PHOSPHATE BUFFER pH 5.5}

Solution I- $13.612 \mathrm{~g}$ of Potassium dihydrogen phosphate in $1000 \mathrm{ml}$ of Distilled Water.

Solution II- $35.08 \mathrm{~g}$ of Disodium hydrogen phosphate in $1000 \mathrm{ml}$ of Distilled Water.

$96.4 \mathrm{ml}$ of Solution I and $3.6 \mathrm{ml}$ of Solution II were mixed together.

\section{STANDARDCURVE OFTAMOXIFEN}

$100 \mathrm{mg}$ of drug was accurately weighed and dissolved in $30 \mathrm{ml}$ methanol and made up to $100 \mathrm{ml}$ with phosphate buffer $\mathrm{pH}$ 5.5. Calibration curve was prepared in a mixture of phosphate buffer and methanol (7:3) at $\lambda \max 265 \mathrm{~nm}$. 


\section{FORMULATION DEVELOPMENT}

\section{Preparation of Tamoxifen Nanosponge:}

Tamoxifen nanosponge was formulated by emulsion solvent diffusion method. Ten batches of nanosponges (NS1- NS10) with varying proportions of hydroxyl ethyl cellulose (HEC) and polyvinyl alcohol (PVA) were taken. The disperse phase consists of Tamoxifen (100mg) and required quantity of HEC dissolved in $20 \mathrm{ml}$ of dichloromethane was slowly added to a specific quantity of PVA in $150 \mathrm{ml}$ of aqueous continuous phase. Then the mixture was stirred at $1000 \mathrm{rpm}$ for 2 hours on a magnetic stirrer (Kemi, India). The nanosponges formed were collected by filtration and dried in oven (Kemi, India) at $40^{\circ} \mathrm{C}$ for 24 hours. Then the dried nanosponges were stored in vacuum desiccator to remove the residual solvent. The composition of nanosponge formulation was tabulated below. The prepared nanosponges were characterized based upon the entrapment efficacy and particle size. ${ }^{8}$

Table 1: Composition of Nanosponge Formulation

\begin{tabular}{lllllllllll}
\hline Component (\% w/w) & NS1 & NS2 & NS3 & NS4 & NS5 & NS6 & NS7 & NS8 & NS9 & NS10 \\
\hline Drug & 1.0 & 1.0 & 1.0 & 1.0 & 1.0 & 1.0 & 1.0 & 1.0 & 1.0 & 1.0 \\
PVA & 1.0 & 1.5 & 2.0 & 2.5 & 3.0 & 3.5 & 4.0 & 3.5 & 4.5 & 4.5 \\
HEC & 1.0 & 1.5 & 2.0 & 2.5 & 3.0 & 3.5 & 4.0 & 4.5 & 3.5 & 4.5 \\
Dichloromethane & 20 & 20 & 20 & 20 & 20 & 20 & 20 & 20 & 20 & 20 \\
Distilled water & 150 & 150 & 150 & 150 & 150 & 150 & 150 & 150 & 150 & 150 \\
\hline
\end{tabular}

Polyvinyl alcohol-(PVA), hydroxyl ethyl cellulose-(HEC)

\section{CHARACTERIZATION OF TAMOXIFEN LOADED NANOSPONGE}

All the formulated Tamoxifen loaded Nanosponge were evaluated for its Drug content, entrapment efficiency, particle size distribution, poly dispersity index, in vitro drug release and kinetics of drug release.

\section{Determination of drug content}

The total drug content of Nanosponge was determined by spectrophotometric analysis.10 milligram equivalent of Tamoxifen loaded Nanosponge taken in a beaker (closed to avoid evaporation) containing (10ml) of Methanol and stirred for30 minutes in magnetic stirrer, $3 \mathrm{ml}$ of that solution is pipette out and that volume was made upto10ml by using pH5.5phosphate buffer to make $1 \mu \mathrm{g} / \mathrm{ml}$ concentration. The absorbance was measured at $265 \mathrm{~nm} \lambda_{\max }$ using UV spectrophotometer. From the absorbance drug content was calculated.

The percentage Drug Content is calculated by following formula:

$$
\% \text { Drug content }=\frac{\text { Practical Drug Content }}{\text { Theoreticaldrug content }} \times 100
$$




\section{Determination of drug entrapment efficiency ${ }^{11}$}

The entrapment efficiency was determined by measuring the concentration of the drug in the supernatant after centrifugation. The unentrapped Tamoxifen were determined by adding 10 mg Tamoxifen loaded Nanosponge in $10 \mathrm{ml}$ of methanol and then the dispersion were centrifuged at 9,000rpm for 30 minutes at $4^{\circ} \mathrm{C}$ using a cooling centrifuge in order to separate entrapped from the unentrapped drug. The free drug concentration in supernatant layer after centrifugation is determined at $\lambda_{\max }(265 \mathrm{~nm})$ using UV Spectrophotometer The percentage entrapment efficiency (\%EE) is calculated by following formula:

$$
\% \mathrm{EE}=\frac{\text { Weight of Initial drug }- \text { Weight of free drug }}{\text { Weight of Initial drug }} \times 100
$$

\section{in- vitro release studies}

The in vitro release of Tamoxifen from Nanosponge was evaluated by the Dialysis Bag diffusion technique. The release studies of Tamoxifen from Nanosponge were performed in Phosphate buffer of pH5.5 and methanol (70:30) 18mg equivalent Tamoxifen Nanosponge were suspended in $10 \mathrm{ml}$ of buffer pH5.5 mixture and placed in the dialysis bag (donor compartment) and sealed at both ends. The dialysis bag were immersed in receptor compartment containing 100ml of buffer mixture, which was stirred at $100 \mathrm{rpm}$ and maintain $32 \pm 2^{\circ} \mathrm{C}$. The receptor compartment was covered to prevent evaporation of the diffusion medium. Samples were taken from the receptor compartment and the same amount were replaced with the diffusion medium. Samples are taken upto 24hrs. Tamoxifen in the samples were measured spectrophotometrically at $\lambda 265 \mathrm{~nm}$. Same procedure was carried out for pure drug and in vitro release were measured spectrophotometrically at $\lambda 265 \mathrm{~nm}$.

\section{SELECTION AND EVALUATION OF OPTIMIZED FORMULATION}

The best formulation selection based on the results obtained from particle size, entrapment efficiency, in-vitro release studies and kinetics of drug release.

\section{FT-IR spectroscopic studies}

The compatibility study was carried out for optimized formulations (F3andF7) using FTIR at wave length range of 4000 to $400 \mathrm{~cm}^{-1}$. Spectrum for optimized formulation were taken and compared.

\section{Morphology of Nanosponge by scanning electron microscopy (SEM) technique}

The Surface Morphology of the Nanosponge can be measured by SEM. The formulations are poured in a circular aluminum stubs using double adhesive tape, and coated with gold in HUS- 
5GB vaccum evaporator and observed in Hitachi S-3000NSEMatan acceleration voltage of 10 $\mathrm{Kv}$ and a magnification of 5000X.

\section{Particle size distribution:}

Particle size (z-average diameter), and poly dispersity index (as a measure of the width of the particle size distribution) of Tamoxifen loaded Nanosponge dispersion is performed by dynamic light scattering also known as photon correlation spectroscopy(PCS) using a Malvern Zetasizer $3000 \mathrm{NanoS}$ (Malvern instruments, $\mathrm{UK}$ ) at $25^{\circ} \mathrm{C}$.

Prior to measurements all samples were diluted using ultra-purified water to yield a suitable scattering intensity. The diluted nanosponge dispersion was poured into disposable sizing cuvette which is then placed in the cuvette holder of the instrument and analyzed. Air bubbles were removed from the capillary before measurement.

\section{Kinetic drug release}

To analyze the drug release mechanism, in-vitro release are fitted into a

Zero-order

First order

Higuchi,

Hixon-Crowellcube root law,

Korsmeyer-peppas model.

\section{STABILITY STUDIES}

The stability studies of the optimized Nanosponge were performed at different conditions of temperature and the effect on physical characteristic, entrapment efficiency and drug content was noted. The Nanosponge were kept in the airtight container and stored at $40 \pm 2^{\circ} \mathrm{C}$ and in Relative humidity $75 \pm 5 \%$ for 45 days. The samples were analyzed for the above parameter in 15 days, 30 days and 45days.

The samples were withdrawn on 15 days, 30days and 45days and checked for changes in Physical appearance and drug content as per ICH QIA (R2) guidelines.

\section{FORMULATION OF TAMOXIFEN LOADED NANOSPONGE GEL}

\section{Formulation of Nanosponge loaded hydrogel:}

Gel forming polymer was soaked in water for 2 hours and then dispersed by agitation with the aid of magnetic stirrer (Kemi, India) to get a uniform dispersion. The stirring was stopped and allowed to stand for 15 minutes to expel the entrapped air. To this aqueous solution, 2\%v/v triethanolamine was slowly added. At this stage, prepared nanosponge and different 
concentration of penetration enhancer (propylene glycol: 5\%-15\%) was added to get the hydrogel ${ }^{13}$. The composition was tabulated in Table 2.

Table 2: Composition of Nanosponge Loaded Hydrogel

\begin{tabular}{lllllll}
\hline Component (\% w/w) & F0 & F1 & F2 & F3 & F4 & F5 \\
\hline Nanosponges & - & 6.0 & 6.0 & 6.0 & 6.0 & 6.0 \\
Tamoxifen & 1.0 & - & - & - & - & - \\
Triethanolamine & 2.0 & 2.0 & 2.0 & 2.0 & 2.0 & 2.0 \\
Propylene glycol & - & - & 5 & 10 & 15 & 20 \\
Carbopol 934 & 1.0 & 1.0 & 1.0 & 1.0 & 1.0 & 1.0 \\
Distilled water (q.s) & 100 & 100 & 100 & 100 & 100 & 100 \\
\hline
\end{tabular}

\section{EVALUATION OF NANOSPONGE GEL}

\section{Physical Appearance}

The prepared gel was examined for clarity, color, homogeneity and the presence of foreign particles.

pH

$2.5 \mathrm{~g}$ of gel was accurately weighed and dispersed in $25 \mathrm{ml}$ of distilled water. The $\mathrm{pH}$ of the dispersion was measured by using a digital $\mathrm{pH}$ meter.

\section{Rheological study}

\section{Viscosity measurement:}

Viscosity was determined by Brook field viscometer. In the present study, spindle no.S64 with an optimum speed of $0.6 \mathrm{rpm}$ was used to measure the viscosity of the preparation.

\section{Content Uniformity:}

The drug content of the prepared gel was carried out by dissolving accurately weighed quantity of gel equivalent to $9 \mathrm{mg}$ of the drug in a beaker containing $10 \mathrm{ml}$ of methanol, stir the solution for 30minutes and centrifuged in High speed cooling centrifuge and $3 \mathrm{ml}$ of the solution is made upto10ml with phosphate buffer pH5.5. The samples were analyzed spectrophotometrically at $\lambda \max 265 \mathrm{~nm}$ against blank using UV-Visible spectrophotometer.

\section{In-vitro Drug Diffusion study}

In-vitro drug diffusion study was studied using dialysis bag. The Nanosponge gel equivalent to $18 \mathrm{mg}$ of the drug was placed in a Dialysis Bag having $8 \mathrm{~cm}$ length and $3 \mathrm{~cm}$ breath, both the sides are tied with thread. This acted as the donor compartment. Then the bag was placed in a beaker containing $100 \mathrm{ml}$ phosphate buffered methanol pH5.5, which acted as receptor compartment. The temperature of the receptor medium was maintained at $37^{\circ} \pm 2^{\circ} \mathrm{C}$ and the medium was stirred at a speed of $100 \mathrm{rpm}$ using a magnetic stirrer. 
$5 \mathrm{ml}$ of the samples were collected at a predetermined time and replenished immediately with the same volume of fresh buffer PB mixture pH5.5. The sink condition was maintained throughout the experiment. The collected samples were analyzed spectrophotometrically at $265 \mathrm{~nm}$ using UV-Visible spectrophotometer.

\section{RESULTS AND DISCUSSION}

Solubility:

Table:3: Solubility

\begin{tabular}{ll}
\hline Solvent & Solubility $(\mathbf{m g} / \mathbf{m l})$ \\
\hline Ethanol & 43.18 \\
Water & 23.59 \\
DMSO & 48.97 \\
Alcohol & 45.27 \\
pH 6.8 Phosphate buffer & 22.36 \\
\hline
\end{tabular}

\section{PRE-FORMULATIONSTUDIES}

The optimization of a formulation can be done only after a thorough investigation of its physicochemical properties of the drug and excipients. The drug and the polymer must be compatible for a successful formulation.

Physical Compatibility

Table 4: Physical compatibility

\begin{tabular}{|c|c|c|c|c|c|c|c|c|}
\hline \multirow[t]{3}{*}{ S. No. } & \multicolumn{8}{|c|}{ Description and condition } \\
\hline & \multirow{2}{*}{$\begin{array}{l}\text { Drug (D) } \\
\text { and } \\
\text { excipients }\end{array}$} & \multirow[t]{2}{*}{ Initial } & \multicolumn{3}{|c|}{$\begin{array}{l}\text { Room temperature (in } \\
\text { days) }\end{array}$} & \multicolumn{3}{|c|}{$\begin{array}{l}40^{\circ} \mathrm{C} \pm 2^{\circ} \mathrm{C} / 75 \pm 5 \% \\
\mathrm{RH}(\text { in days })\end{array}$} \\
\hline & & & 10 & 20 & 30 & 10 & 20 & 30 \\
\hline 1. & Drug & $\mathbf{N C}$ & NC & $\mathbf{N C}$ & NC & $\mathbf{N C}$ & $\mathbf{N C}$ & $\mathbf{N C}$ \\
\hline 2. & $\mathrm{D}+\mathrm{HEC}$ & NC & NC & NC & NC & NC & $\mathbf{N C}$ & $\mathbf{N C}$ \\
\hline 3. & $\mathrm{D}+\mathrm{PVA}$ & $\mathbf{N C}$ & NC & NC & NC & NC & $\mathbf{N C}$ & $\mathbf{N C}$ \\
\hline
\end{tabular}

\section{Inference}

The drug and the excipients of the formulation are physically compatible with each other. They were evaluated for 10,20 and 30 days at room temperature and at $400^{\circ} \mathrm{C} \pm 2^{\circ} \mathrm{C} / 75 \pm 5 \%$ Relative Humidity.

\section{Chemical compatibility}

FT-IR spectroscopy gives the possible information about the interaction between the drug and Polymer.

\section{Drug-Polymer compatibility studies}

FT-IR Spectroscopic studies 
The compatibility between drug and Polymer was confirmed using FT-IR Spectroscopy. Infrared spectroscopic analysis for drug (Tamoxifen), Polymer, Drug-Polymer admixture was carried out.

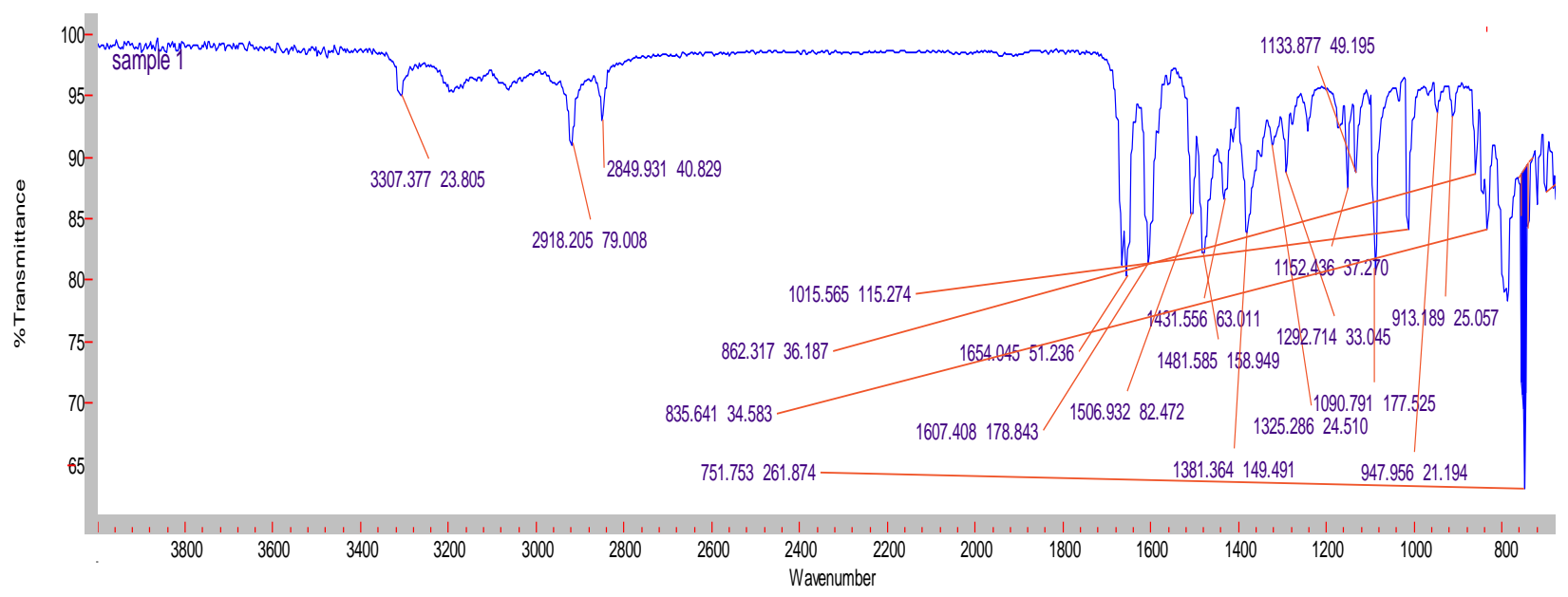

Figure 1: FTIR spectrum of pure drug

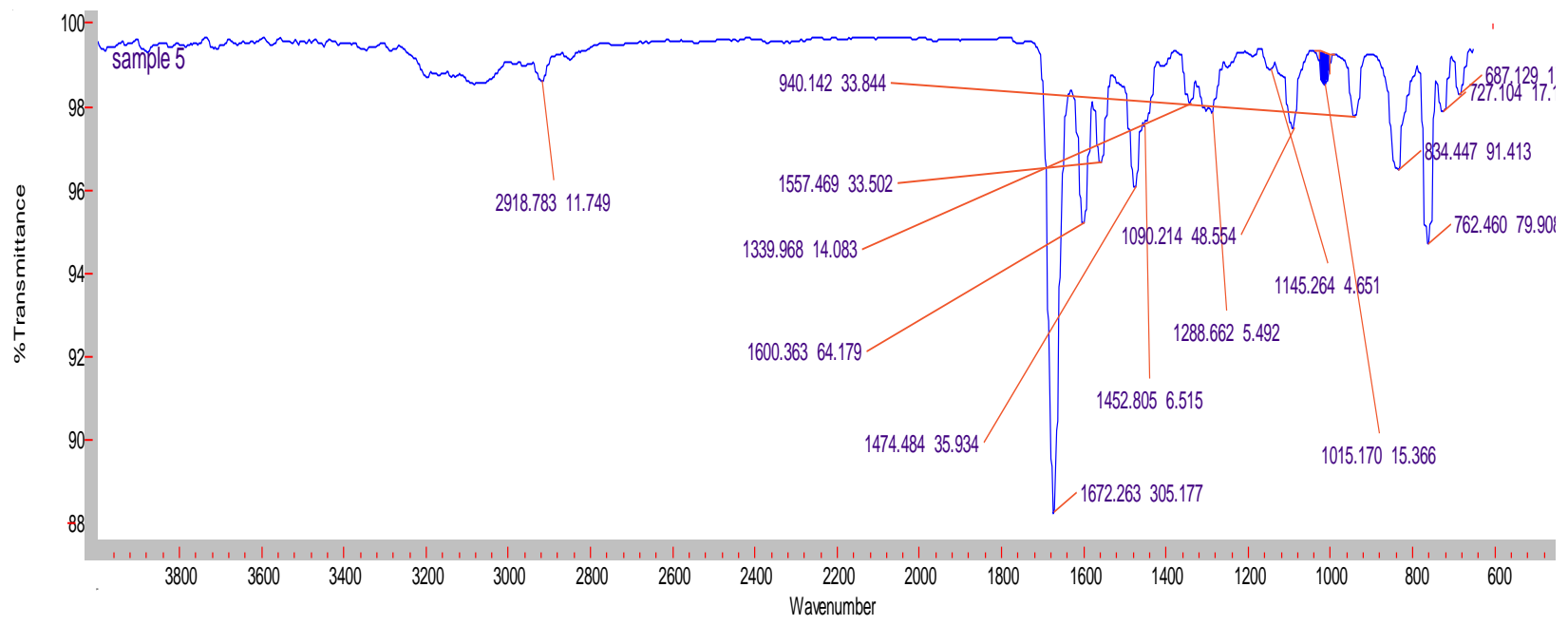

Figure 2: FTIR spectrum of hydroxyl ethyl cellulose

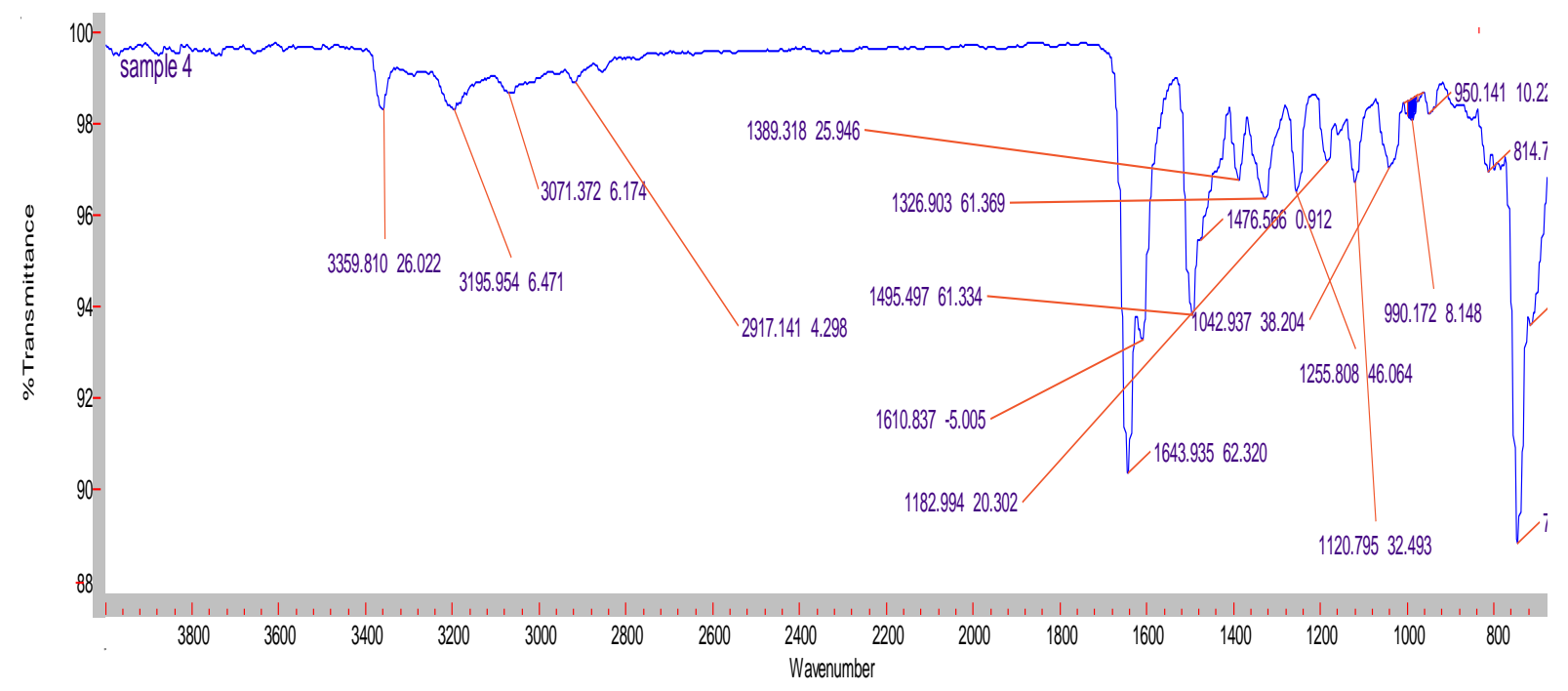

Figure 3: FTIR spectrum of PVA 


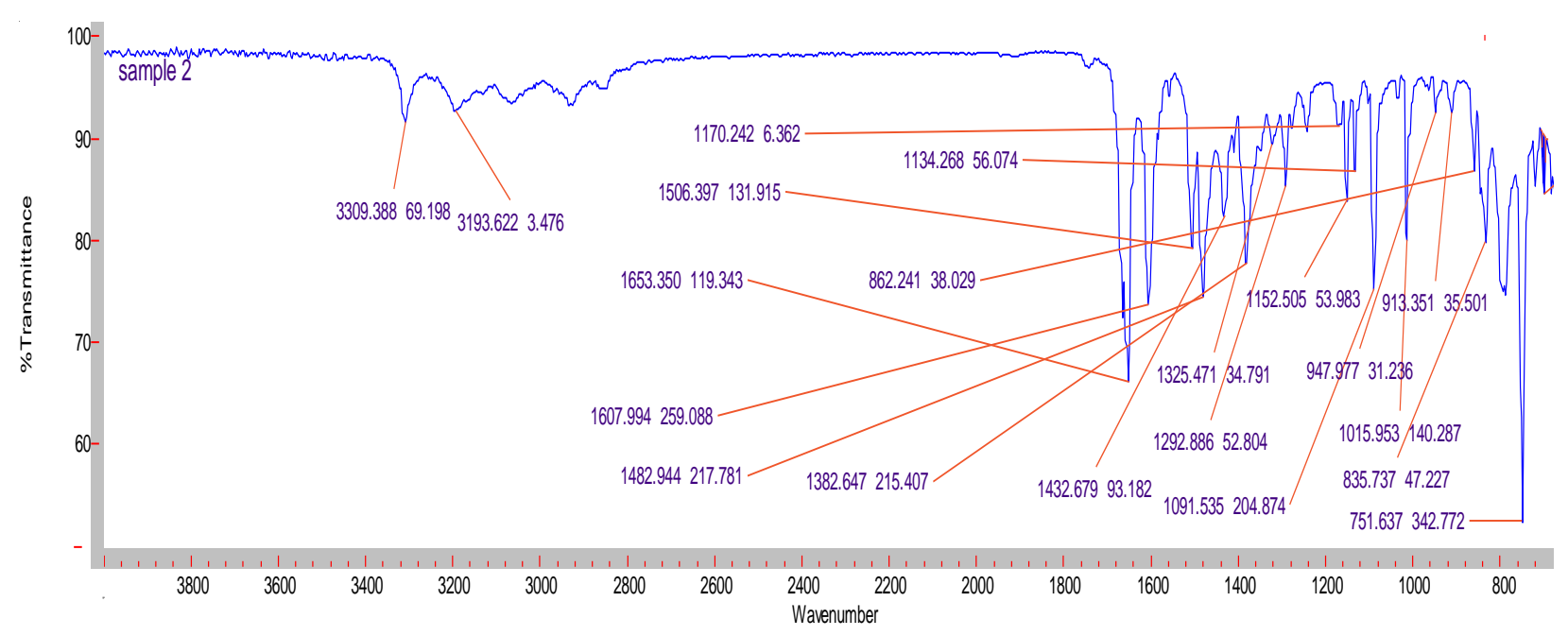

Figure 4: FTIR spectrum of TAMOXIFEN and hydroxyl ethyl cellulose

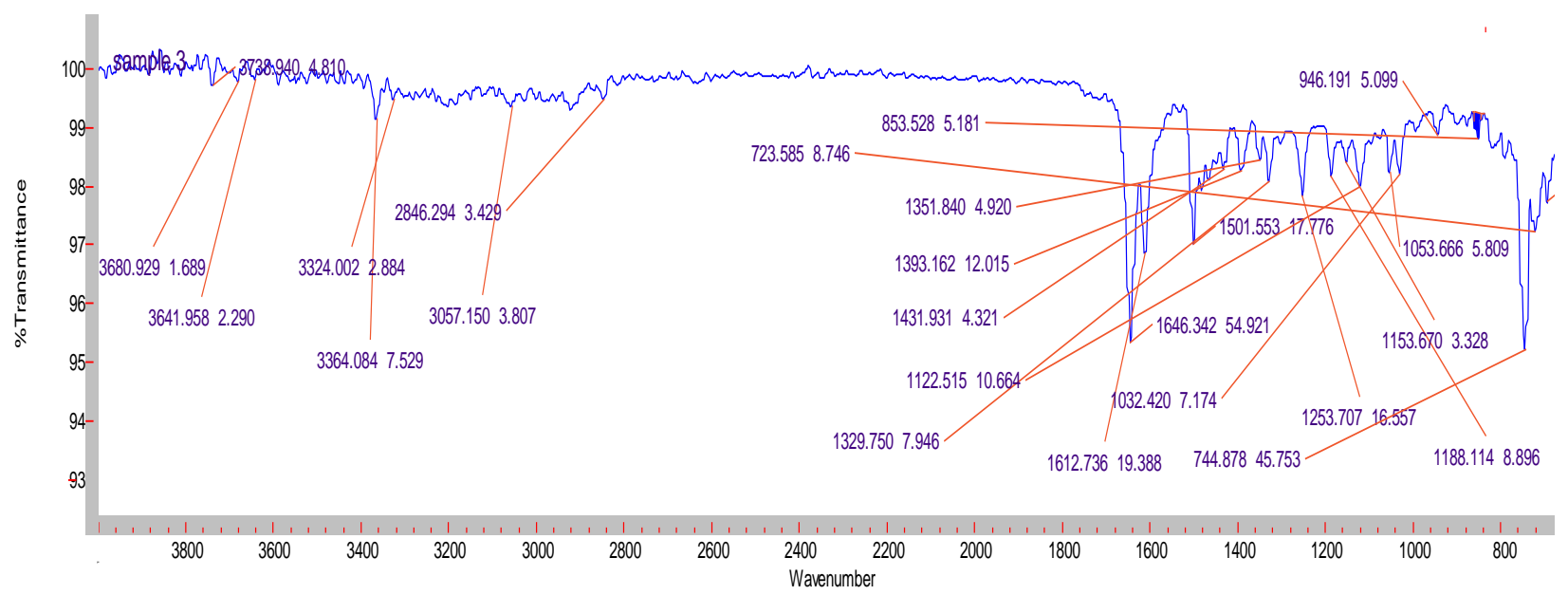

Figure 5: FTIR spectrum of TAMOXIFEN and PVA

Figure above given shows the FTIR spectra of tamoxifen citrate, HEC and PVA (excipients), and mixture of drug and excipients and a freshly prepared formulation. Variation in peaks was noticed between 1300 and 1200 wave numbers $\left(\mathrm{cm}^{-1}\right)$ in nanoparticles. The region is the IR stretching vibration zone of functional groups such as C-O (alcohol) and C-N.21 Formation of weak physical bonds such as hydrogen bonding, bond due to Van der Waals forces or dipole moment might take place between $\mathrm{C}-\mathrm{N}$ present in the drug molecule and - $\mathrm{OH}$ present in HEC. The data suggest that there was no chemical interaction between the drug and the excipients since no shifting of characteristic peaks of drug as well as excipients was noticed as the shifting of characteristic peak is claimed as chemical interaction ${ }^{24}$.

DSC STUDIES 


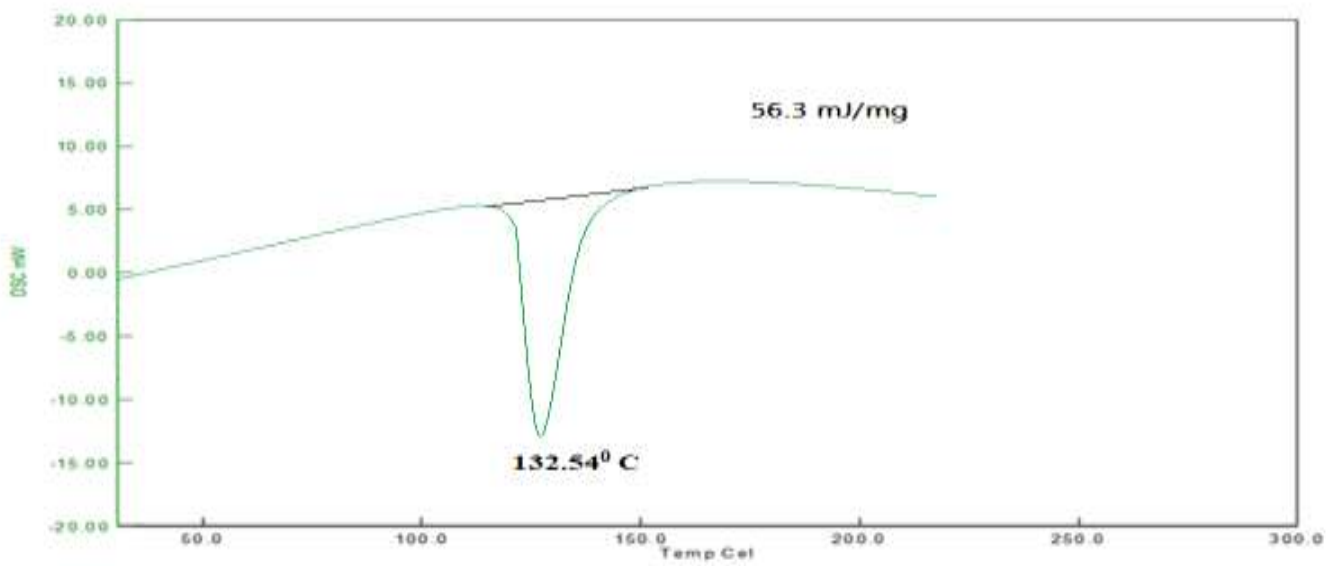

DSC spectrum of pure drug

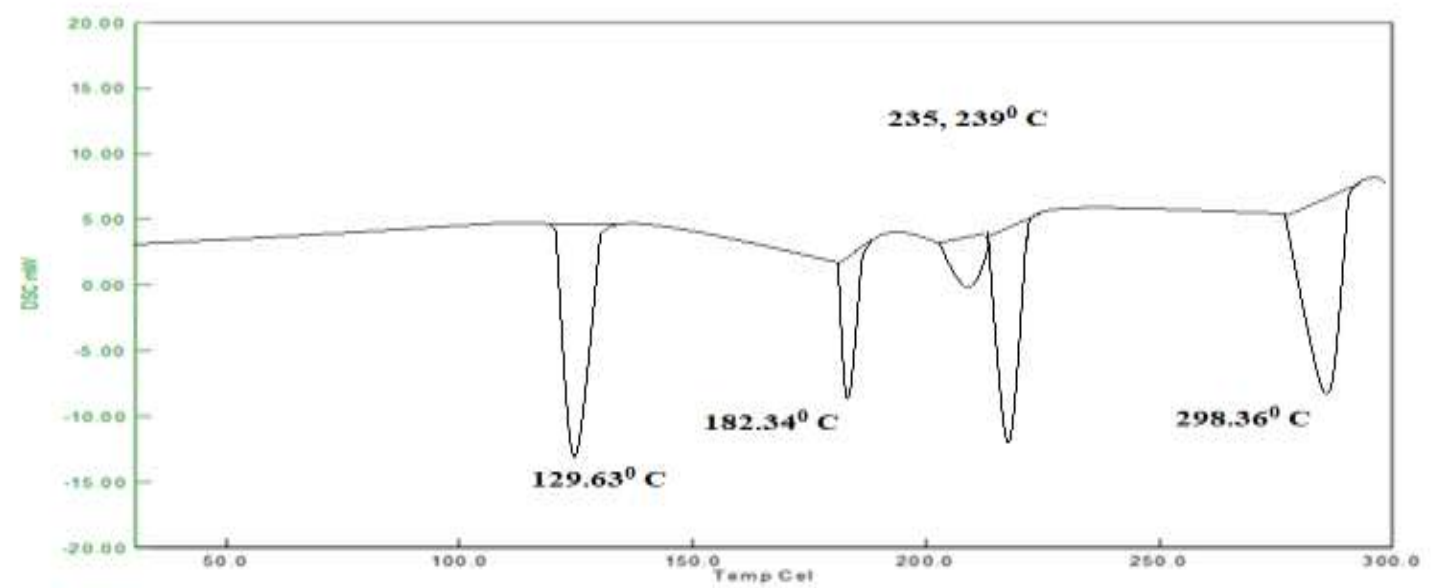

DSC spectrum of pure drug with polymer mix

\section{STANDARDCURVE OF TAMOXIFEN}

The UV spectrometric method was used to analyze Tamoxifen. The absorbance of the drug in phosphate buffered methanol pH5.5. (70:30) was measured at a wave length of $265 \mathrm{~nm}$.

\section{CALIBRATIONCURVE}

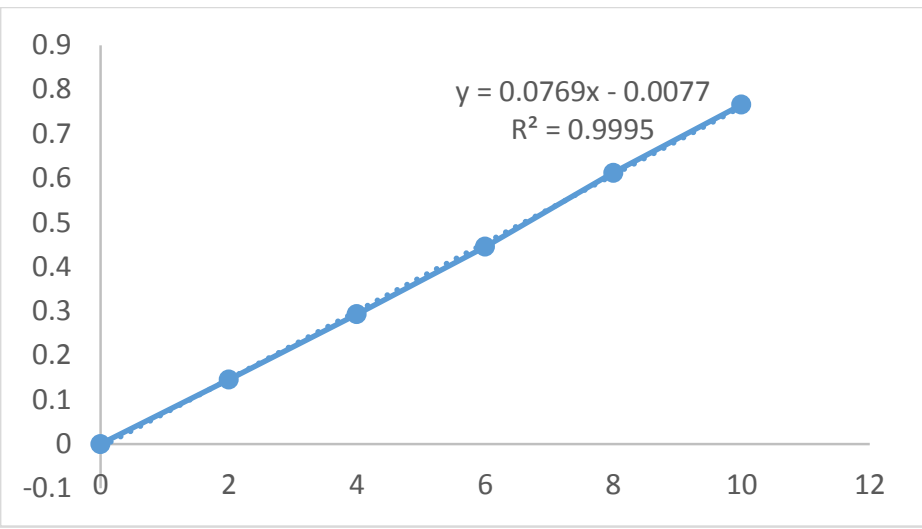

Figure 6: Calibration curve for Tamoxifen. 


\section{Inference}

It was found that the solutions of Tamoxifen in Phosphate buffered methanol pH5.5 show

linearity $\left(\mathrm{R}^{2}=0.999\right)$ in absorbance at concentrations of $2-10 \mathrm{mcg} / \mathrm{ml}$ and obey Beer Lambert's law.

\section{FORMULATION OF TAMOXIFEN NANOSPONGE}

Tamoxifen Nanosponge was prepared by homogenization technique followed by centrifugation.

CHARACTERIZATIONOF NANOSPONGE

Drug content and entrapment Efficiency

Table 5: Drug content and Entrapment Efficiency of Tamoxifen Nanosponge

\begin{tabular}{lll}
\hline $\begin{array}{l}\text { Formulation } \\
\text { Code }\end{array}$ & $\begin{array}{l}\text { \%Drug Content } \\
(\boldsymbol{\%} \mathbf{w} / \mathbf{v})\end{array}$ & $\begin{array}{l}\text { \% Entrapment } \\
\text { Efficiency }(\% \mathbf{w} / \mathbf{v})\end{array}$ \\
\hline F1 & $64.52 \pm 0.129$ & 68.97 \\
F2 & $73.1 \pm 0.623$ & 78.41 \\
F3 & $80.26 \pm 0.286$ & 88.49 \\
F4 & $\mathbf{9 1 . 5 4 \pm 1 . 1 8 3}$ & $\mathbf{9 8 . 6 8}$ \\
F5 & $62.90 \pm 1.369$ & 68.58 \\
F6 & $80.56 \pm 0.366$ & 97.75 \\
F7 & $82.81 \pm 0.221$ & 96.12 \\
F8 & $\mathbf{9 5 . 9 4 \pm 0 . 5 6 5}$ & $\mathbf{9 9 . 4 4}$ \\
F9 & $83.75 \pm 0.536$ & 88.59 \\
F10 & $86.60 \pm 0.807$ & 87.70 \\
\hline
\end{tabular}

\section{Inference}

The Drug content of the formulations was observed to be from 62.90 to 95.94 . The entrapment efficiency was found to be 68.97 to 99.44 . The highest entrapment efficiency was observed with 98.68 and 99.44 for the formulations F4andF8.

\section{SURFACE MORPHOLOGY OF NANOSPONGE}

Surface morphology of Nanosponge was measured by Scanning Electron Microscopy (SEM).

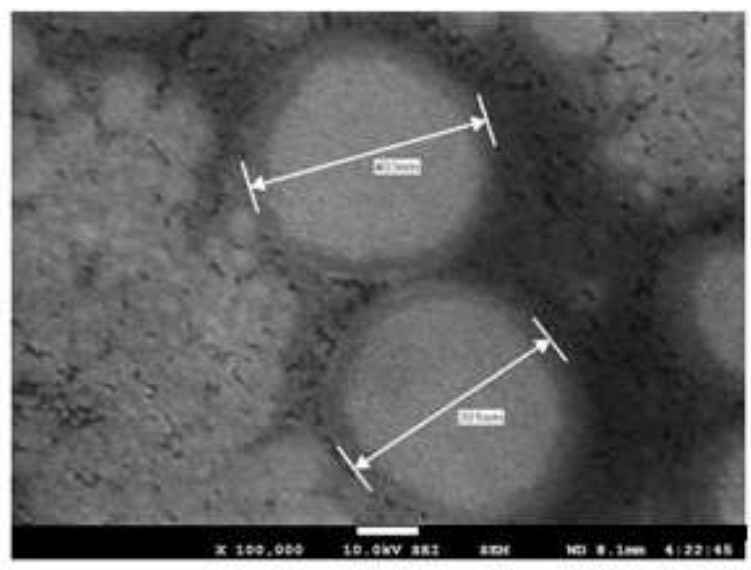

Figure-7: SEM image of Optimized Formulation (F4) 


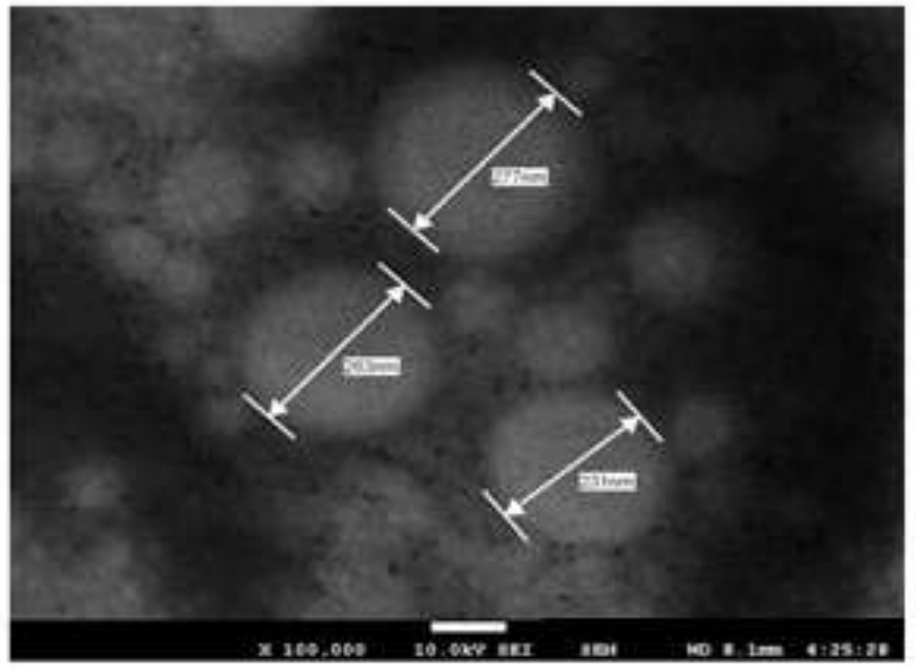

Figure-8: SEM image of optimized Formulation (F8)

\section{Inference}

SEM picture shows the formation of Spherical Nanoparticles. The average particle size of Tamoxifen loaded Nanosponge F4 is $91.34 \mathrm{~nm}$ and the poly dispersity index was found to be 0.196

The average particle size of Tamoxifen Nanosponge F8was $201.34 \mathrm{~nm}$ and the poly dispersity index was found to be 0.178 in- vitro drug release of Tamoxifen

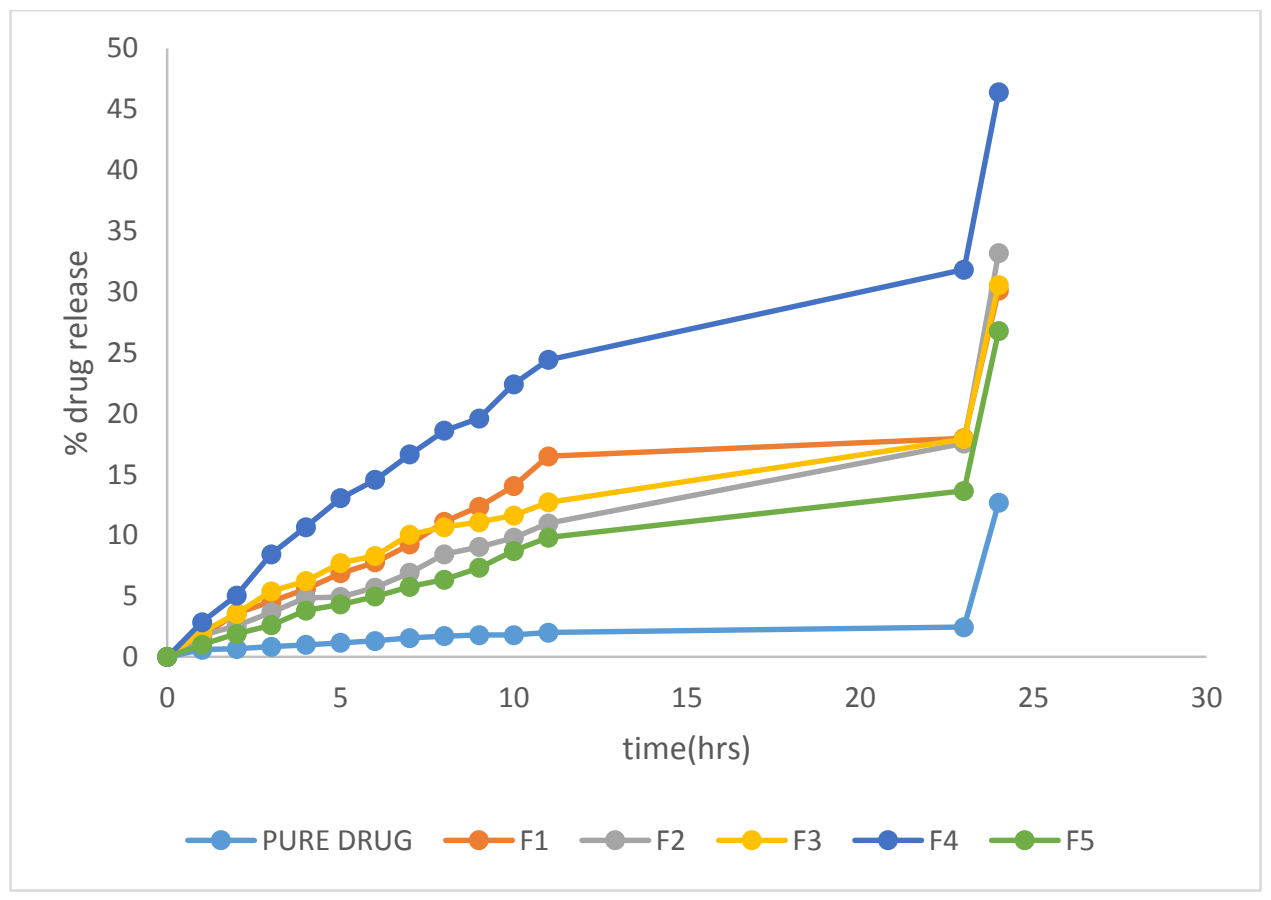

Figure 9: in- vitro drug release of Tamoxifen Nanosponge and pure drug 


\section{in-vitro DRUG RELEASE OF PURE DRUG AND TAMOXIFEN NANOSPONGE}

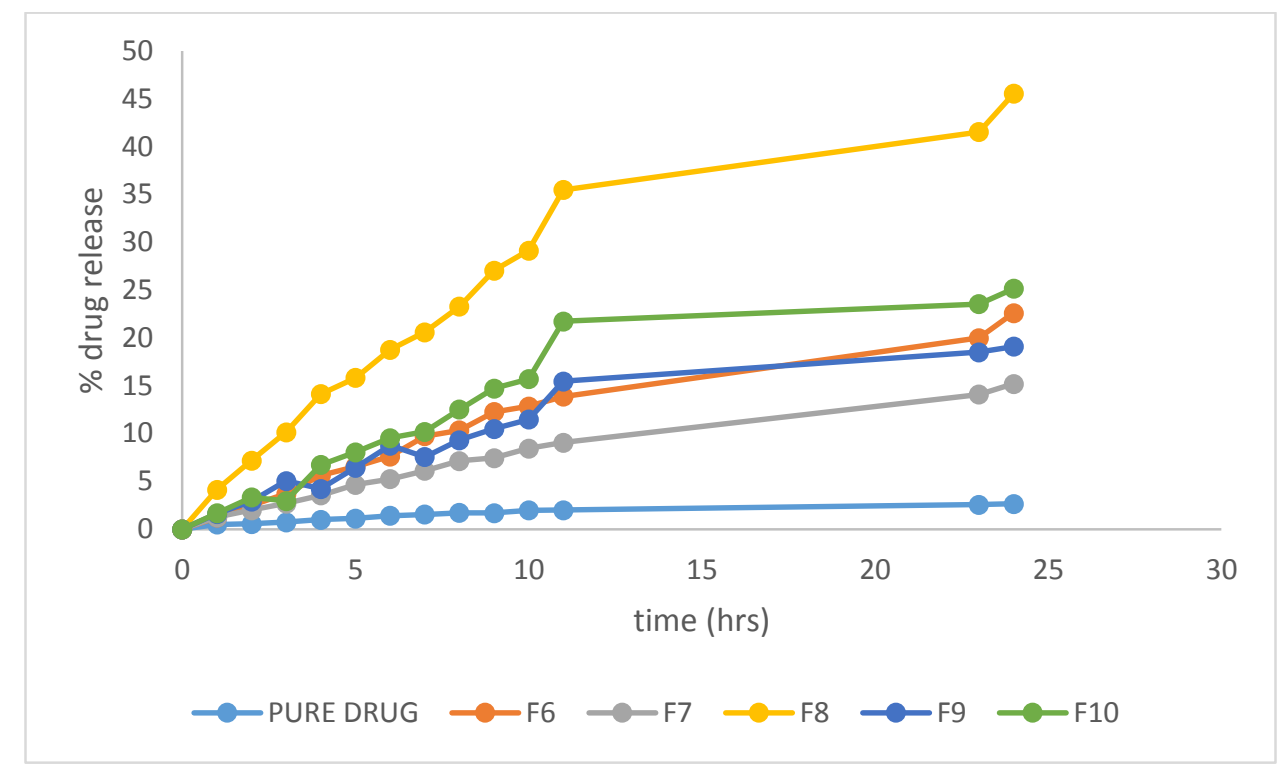

Figure 10: in-vitro drug release of Tamoxifen Nanosponge with pure drug.

\section{Inference}

The in-vitro release of the formulations was observed to be between $2.66 \%$ to $46.39 \%$ the results shown that the increase in polymer concentration increase the drug release and then it is decreased as described by Dr Prathama Srinivas et al. From the result it was observed that the formulations F4 and F8 Showed sustained release of drug.

Table 6: Evaluation of Gel

\begin{tabular}{lllllll}
\hline S.No. & Code & $\begin{array}{l}\text { Physical } \\
\text { appearance }\end{array}$ & $\begin{array}{l}\% \\
\text { Drug } \\
\text { content }\end{array}$ & $\begin{array}{l}\text { Viscosity } \\
\text { (cps) }\end{array}$ & pH & $\begin{array}{l}\text { \% Drug } \\
\text { release }\end{array}$ \\
\hline 1. & G1 & Good & 84.55 & $2.839 \times 10^{6}$ & 4.98 & 28.77 \\
2. & G2 & Good & 81.10 & $2.823 \times 10^{6}$ & 4.82 & 22.12 \\
\hline
\end{tabular}

\section{Inference}

The in-vitro release of the Gel formulation of F3 and F7 was compared with marketed sample of Tamoxifen cream, and the release of Nanosponge gel (G1 and G2) was $23.15 \%$ and $28.88 \%$ respectively. The release of gel was increased due to the decreased particle size and increased surface areas described by Rawia M. Khalil et al. 


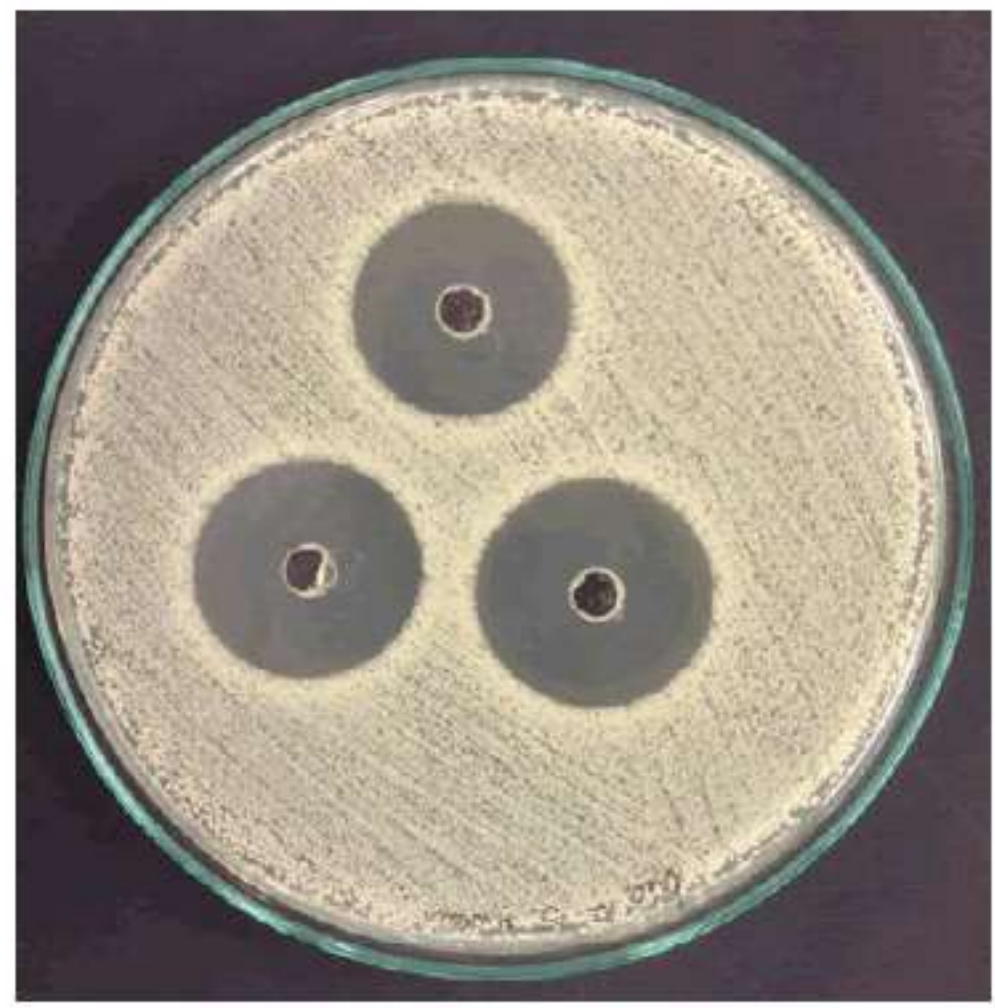

Figure-11: Diffusion Study by agar plate method

Optimized formulation G1-F4 passed $1.62 \mathrm{cms}$ in agar medium showing good diffusion properties
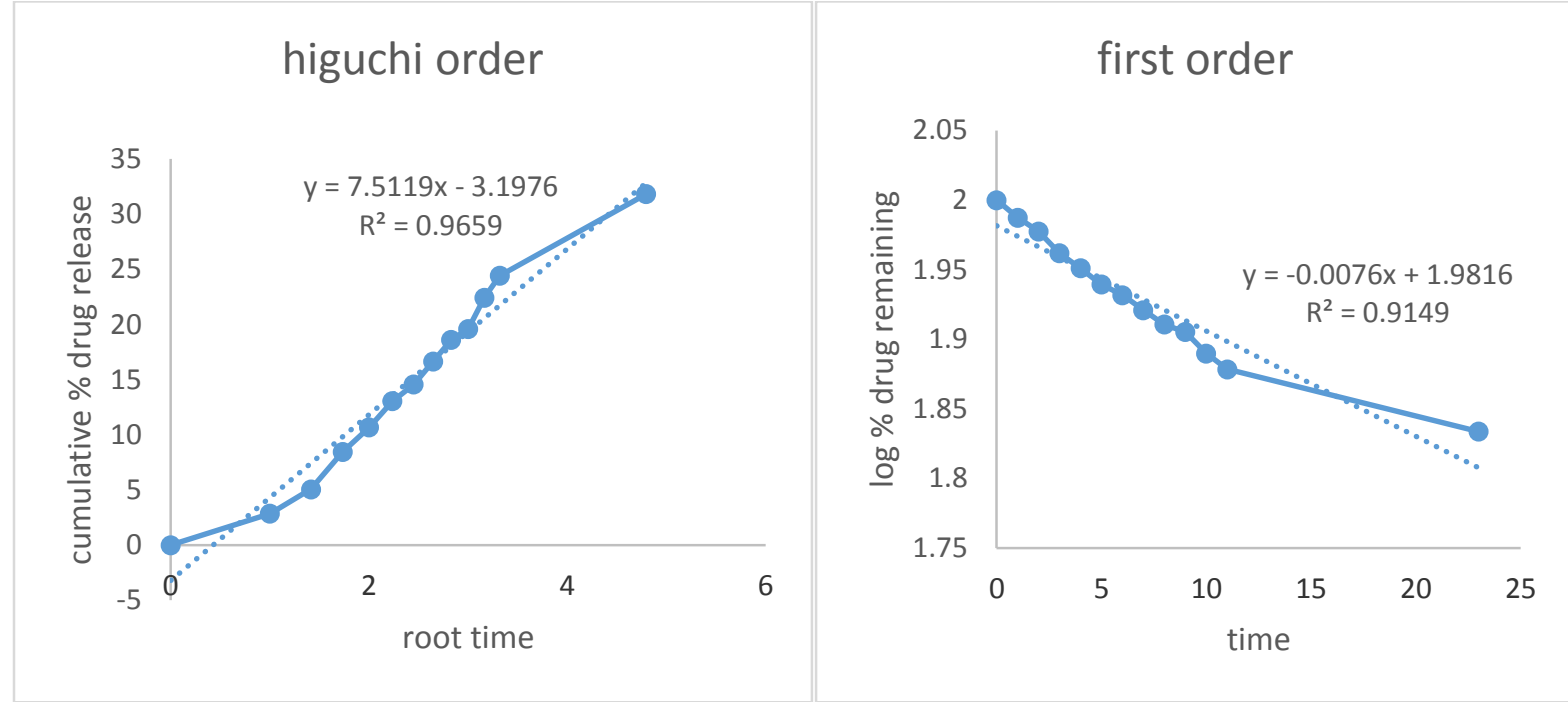

Following the above data it was observed that the formulation $\mathrm{F} 4$ followed first order release with Higuchi mechanism 
Table 7: stability study of optimized formulation g1-f4

\begin{tabular}{|c|c|c|c|c|c|c|}
\hline \multirow{2}{*}{$\begin{array}{l}\text { Temperature } \\
\text { Parameters }\end{array}$} & \multicolumn{2}{|c|}{$\begin{array}{c}\text { Room temperature (30 } \\
\left. \pm 2^{\circ} \mathrm{C}\right)\end{array}$} & \multicolumn{2}{|c|}{ Refrigerator $\left(4 \pm 2^{\circ} \mathrm{C}\right)$} & \multicolumn{2}{|c|}{$\begin{array}{c}\text { Accelerated }\left(40 \pm 2^{\circ} \mathrm{C}\right. \\
75 \pm 5 \% \mathrm{RH})\end{array}$} \\
\hline & $\begin{array}{l}\text { Physical } \\
\text { appearance }\end{array}$ & $\begin{array}{l}\text { Percentage } \\
\text { drug } \\
\text { content } \\
(\%)\end{array}$ & $\begin{array}{l}\text { Physical } \\
\text { appearance }\end{array}$ & $\begin{array}{l}\text { Percentage } \\
\text { drug } \\
\text { content } \\
(\%)\end{array}$ & $\begin{array}{l}\text { Physical } \\
\text { appearance }\end{array}$ & $\begin{array}{l}\text { Percentage } \\
\text { drug } \\
\text { content } \\
(\%)\end{array}$ \\
\hline $\begin{array}{l}\text { Freshly } \\
\text { prepared }\end{array}$ & $\begin{array}{l}\text { Transparent } \\
\text { and smooth }\end{array}$ & 91.35 & $\begin{array}{l}\text { Transparent } \\
\text { and smooth }\end{array}$ & 91.66 & $\begin{array}{l}\text { Transparent } \\
\text { and smooth }\end{array}$ & 91.44 \\
\hline $7^{\text {th }}$ day & $\begin{array}{l}\text { Transparent } \\
\text { and smooth }\end{array}$ & 91.32 & $\begin{array}{l}\text { Transparent } \\
\text { and smooth }\end{array}$ & 91.64 & $\begin{array}{l}\text { Transparent } \\
\text { and smooth }\end{array}$ & 91.24 \\
\hline $15^{\text {th }}$ day & $\begin{array}{l}\text { Transparent } \\
\text { and smooth }\end{array}$ & 91.16 & $\begin{array}{l}\text { Transparent } \\
\text { and smooth }\end{array}$ & 91.37 & $\begin{array}{l}\text { Transparent } \\
\text { and smooth }\end{array}$ & 91.15 \\
\hline $30^{\text {th }}$ day & $\begin{array}{l}\text { Transparent } \\
\text { and smooth }\end{array}$ & 91.10 & $\begin{array}{l}\text { Transparent } \\
\text { and smooth }\end{array}$ & 91.28 & $\begin{array}{l}\text { Transparent } \\
\text { and smooth }\end{array}$ & 90.46 \\
\hline $60^{\text {th }}$ day & $\begin{array}{l}\text { Transparent } \\
\text { and smooth }\end{array}$ & 91.09 & $\begin{array}{l}\text { Transparent } \\
\text { and smooth }\end{array}$ & 91.12 & $\begin{array}{l}\text { Transparent } \\
\text { and smooth }\end{array}$ & 90.12 \\
\hline $90^{\text {th }}$ day & $\begin{array}{l}\text { Transparent } \\
\text { and smooth }\end{array}$ & 90.98 & $\begin{array}{l}\text { Transparent } \\
\text { and smooth }\end{array}$ & 91.06 & $\begin{array}{l}\text { Transparent } \\
\text { and smooth }\end{array}$ & 89.95 \\
\hline
\end{tabular}

Based on the results from the stability studies it was confirmed that the prepared formulation is stable throughout the entire testing period as the drug content levels were constant for most of the time.

\section{CONCLUSION}

Tamoxifen is one of the selective estrogen receptor modulators (SERM) with tissue-specific activities for the treatment and prevention of estrogen receptor positive breast cancer. Tamoxifen acts as an anti-estrogen (inhibiting agent) in the mammary tissue, but as an estrogen (stimulating agent) in cholesterol metabolism, bone density, and cell proliferation in the endometrium. The drug and the excipients of the formulation are physically compatible with each other. They were evaluated for 10,20 and 30 days at room temperature and at $40^{\circ} \mathrm{C} \pm 2^{\circ} \mathrm{C} / 75 \pm 5 \%$ Relative Humidity. The FTIR data suggest that there was no chemical interaction between the drug and the excipients since no shifting of characteristic peaks of drug as well as excipients was noticed as the shifting of characteristic peak is claimed as chemical interaction. The in-vitro release of the formulations was observed to be between $2.66 \%$ to $46.39 \%$ the results shown that the increase in polymer concentration increase the drug release and then it is decreased as described by Dr Prathama Srinivas et al. From the result it was observed that the formulations F4 and F8 Showed sustained release of drug. Following the drug release kinetic data it was observed that the formulation F4 followed first order release with higuchi mechanism 


\section{REFERENCES}

1. S.P. Vyas, R.K. Khar. Targeted and Controlled Drug Delivery-Novel Carrier Systems: Molecular Basis of Targeted Drug Delivery. CBS Publishers and Distributors; New Delhi: 2012: 38- 40.

2. David F: Nanosponge drug delivery system more effective than direct injection. swww.physorg.com 20.12.2011.

3. Krishna moorthy K., Rajappan M. Nanosponges: A novel class of drug delivery systemreview. J Pharm Pharm Sci 2012; 15(1):103-11.

4. Trotta F, Cavalli R, Tumiatti W, Zerbinati O, Rogero C, Vallero R:Ultrasound-assisted synthesis of Cyclodextrin-based Nanosponges. EP 1786841 B1; 2013.

5. Selva muthukumar S, Anandam S, Kannan K, Manavalan R. Nanosponges: A Novel Class of Drug Delivery System- Review. JPharm Pharmaceut Sci. 15(1): 2012; 103-111.

6. Patricia Vsan Arnum: Nanosponges, a controlled - release Nanoparticle system, shows promise in targeted drug delivery. Pharmatech.com. 35(5): 2011; 56-60.

7. Trotta F, Tumiatti V, Cavalli R, Rogero C,Mognetti B, Berta G: Cyclodextrin-based Nanosponges as a vehicle for Antitumoral drugs. WO 2009/003656 A1; 2009.

8. Liang L, De-Pei L, Chih-Chuan L: Optimizing the delivery systems of chimeric RNA. DNA oligonucleotides beyond general oligonucleotide transfer. Eur. J. Biochem 2012; 269: 5753-5758.

9. Jenny A., Merima P., Alberto F., Francesco T: Role of $\beta$ - Cyclodextrin Nanosponges in polypropylene photooxidation Carbohydrate Polymers. 2011, 86:127- 135.

10. Lala R, Thorat A, Gargote C: Current trends in B- cyclodextrin based drug delivery systems. Int J Res Ayur Pharm, 2011; 2(5): 1520-1526.

11. Patel G and Patel JK: Use of a Microsponge in Drug Delivery Systems. Pharmaceutical processing 2008; 158.

12. Khopade AJ, Jain S and Jain NK: "The Microsponge”. Eastern Pharmacist 2012; 49-53.

13. Nimisha Jain, V Kusum Devi, Raman Dang, Uday Bhosale: Micro Sponges: A Novel Drug Delivery System. Vol 15, Issue 81, March-April, 2013.

14. Ajay Vishwakarma et al: Nanosponges: A Beneficiation for Novel Drug Delivery /Int.J.PharmTech Res.2014, 6(1), pp 11-20. 
15. Sharma r, Roderick b and Pathak k: Evaluation and kinetics and mechanism of drug release from Econazole Nitrate Nanosponges loaded carbopol hydrogel. indian $\mathrm{j}$ of pharm edu and research (2011) 45:25-31

AJPHR is

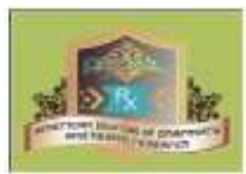

Peer-reviewed

monthly

Rapid publication

Submit your next manuscript at editor@ajphr.com / editor.ajphr@gmail.com 